JASEM ISSN 1119-8362

All rights reserved
Full-text Available Online at www.bioline.org.br/ja
J. Appl. Sci. Environ. Manage. September, 2007

Vol. 11(3) 69 - 74

\title{
Utilization of Plant Refuses as Component of Heavy Metal Ion Sensors in Water Samples
}

\section{*ELMER-RICO E. MOJICA; JOSE RENE L. MICOR}

\author{
Institute of Chemistry, College of Arts and Sciences, University of the Philippines Los Baños, College, Laguna, Philippines
}

Email: elmericomojica@yahoo.com

\begin{abstract}
Waste materials like fruit and vegetable refuses were utilized as component of sensors capable of detecting heavy metals like lead ions and mercury ions by electrochemical method. The ability of the fabricated sensors to detect the presence of heavy metals was analyzed using electrochemical methods like cyclic voltammetry and differential pulse anodic stripping voltammetry. Results showed that the fabricated electrode were able to detect the presence of mercury and lead ions in aqueous solutions. @JASEM
\end{abstract}

Several heavy metals coming mostly from mining wastes and industrial discharges have been found to contaminate our natural waters (Schalcsha et al., 1998). Both the chemically combined forms as well as the elemental form of these metals are toxic (Manahan, 1993). Acute lead, mercury, cadmium, chromium, and copper poisoning in humans causes severe dysfunction in the renal, reproductive, and nervous systems (Berman, 1980). In addition, chronic exposure to these contaminants present even at low concentrations in the environment can prove to be harmful to the human health (Wyatt et al., 1998).

There are several methods used to detect these metals, of which atomic absorption spectrometry (AAS) is the most popular. However, the cost of analysis, the unavailability of equipment, maintenance, sample pre-treatment and large concentrations of solutions limit their application. An alternative method for the detection of these metals is the use of chemically modified carbon paste electrodes (CMCPE). The CMCPE are a class of metal sensors which are relatively easy to prepare and gives a stable response. The concept of chemically modified carbon paste electrodes was a product out of the desire to manipulate the chemical nature of the electrode surface by incorporating a modifying agent. Through this, the electrode assumes the desirable properties of the modifier in binding metals wherein enhanced selectivity, sensitivity and over-all stability is achieved.

Fruits and vegetable refuse (part of plants which have no economic use) like peelings from banana, apple and potato and cabbage and kangkong stems are waste materials which are readily available and of no use except as source of organic matter when left to decay in soil. Plant parts which are of no economical use also contain the materials responsible for the binding of heavy metals. Previous studies have proved that plants are capable of binding heavy metals (Velasco-Alinsug et al 2005; Yang et al 2005). The discovery of metal hyper-accumulating properties in certain plants made way for the *Correspondence: Email: elmericomojica@yahoo.com potential of using plant based system for treatment of wastes containing metals (Ensley, 2000). It has been shown that some plant species have the ability to accumulate elevated amounts of toxic heavy metals (Blaylock and Huang, 2000; Reeves and Baker, 2000). Some varieties of Thlaspi and ecotypes of Silene vulgaris have been found to accumulate cadmium (Ernst et al., 2000; Brown et al., 1994). Larrea tridentata, a desert inhabitant shrub (creosote bush) accumulates copper (Gardea-Torredey 2001) and species of alfalfa plants (Medicago sativa L.) and Euryale ferox Salisb. accumulates cadmium, chromium, and copper (Rai et al., 2002; Peralta et al., 2001; Peralta-Videa et al., 2002).

The use of plant refuses as modifiers in CMCPE is due to the fact that they possess an electrochemically or chemically active moiety. These moieties could be any of the following: redox or ligand sites, ionexchange sites, enzyme active sites; all of which possesses certain functionalities or donor groups. Pineapple peelings were successfully used as a modifier of a voltammetric sensor for lead ions (Mojica et al 2006). The purpose of this study is to utilize plant waste materials as components of metal sensors. Sensors were fabricated utilizing these waste materials and their performances were characterized by electrochemical method in terms of cyclic voltammetry (CV) and differential pulse anodic stripping voltammetry (DPASV).

\section{MATERIALS AND METHODS}

Different waste products from various sources were collected. Waste materials such as peelings from, apple (Malus domestica), banana (Musa sapientum L.) and potato (Solanum tuberosum) and stems from cabbage (Brassica oleracea L. var capitata) and kangkong (Ipomoea aquatica Forsk) were sliced into small sizes and freeze dried. Powdered forms of these waste materials were collected and kept on freezer. Each product from waste material was then thoroughly mixed with graphite powder and mineral oil. A $100 \mathrm{mg}$ mixture of graphite (Sigma) powder and the different modifiers were mixed with 
approximately $20 \mathrm{uL}$ of Nujol oil to form a paste. A portion of the paste was packed into the end of hard plastic tube where a copper rod was inserted to establish electrical contact (Figure 1). The fabricated electrodes were then used as the working electrode.

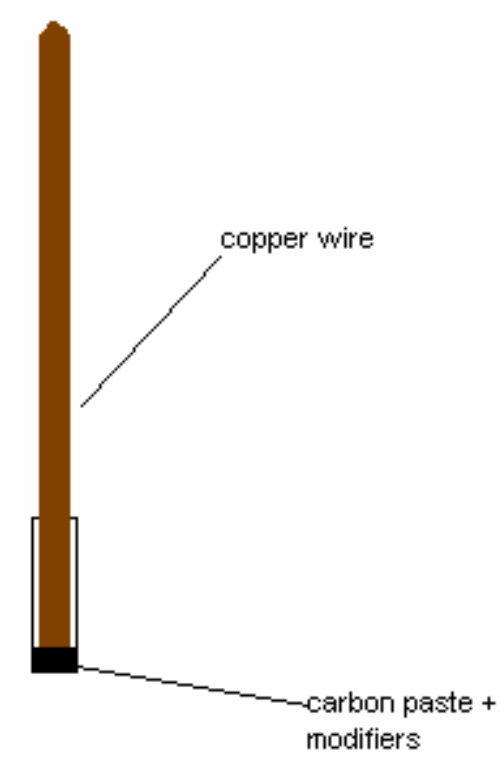

Fig 1. A diagram of modified carbon paste electrode. This modified electrode contains carbon powder, mineral oil and modifiers from plant refuse.

All electrochemical analysis were carried out in a three-electrode cell containing the auxiliary electrode (platinum wire, the reference electrode $(\mathrm{Ag} / \mathrm{AgCl}$ electrode) and the working electrode (prepared electrode) connected to a Metrohm 693VA processor (Figure 2). The processor is interfaced to a personal computer via a RS232 connection, which converts the generated data into an ASCII format. The data obtained was processed using Microcal Origin version 5 .

Cyclic voltammetric measurements were performed with each prepared electrode to evaluate the potential window and reversibility of any redox reaction. Cyclic voltammetry was also used to determine the presence of heavy metals in different prepared solutions (cadmium, cobalt, lead, mercury and nickel at $1000 \mu \mathrm{g} / \mathrm{l})$. Differential pulse anodic stripping voltammetric measurements were made on each electrode before and after accumulation in different metal analytes (cadmium, cobalt, lead, mercury and nickel at $100 \mu \mathrm{g} / \mathrm{l})$. Preconcentration was done by immersing the sensor on the metal solution for 5 minutes in an open circuit. The metal solution was stirred in order to achieve complete quantitative deposition by maintaining constant transport of the metallic ions from the bulk of the metal solution towards the surface of the metal sensor.

The parameters used for the DPASV on the different heavy metals as follows: U. amplitude: $50 \mathrm{Mv}$, Rot Speed: 0/min, step: $\quad 0.20 \mathrm{~s}$, t. meas: $16.7 \mathrm{~ms}$, U. meas: $-1000 \mathrm{mV}$, t. pulse: $33.3 \mathrm{~ms}$, U. start: -1000 $\mathrm{mV}$, U step: $10 \mathrm{mV}$, U. end: $1000 \mathrm{mV}$, Sweep rate: $50 \mathrm{mV} / \mathrm{s}$

\section{RESULTS AND DISCUSSION}

The electrochemistry of the prepared metal sensors with different waste materials as modifiers was investigated. Cyclic voltammetry (CV) was performed on all the prepared modified sensors to determine their potential window. $\mathrm{CV}$ is the most widely used technique for acquiring qualitative information about electrochemical reactions due to its ability to rapidly provide considerable information on the thermodynamics of redox processes and the kinetics of heterogeneous electron-transfer reactions, and on coupled chemical reactions or adsorption processes. In addition, $\mathrm{CV}$ offers a rapid location of redox potentials of the electroactive species, and convenient evaluation of the effect of media upon the redox process (Wang 2000). 


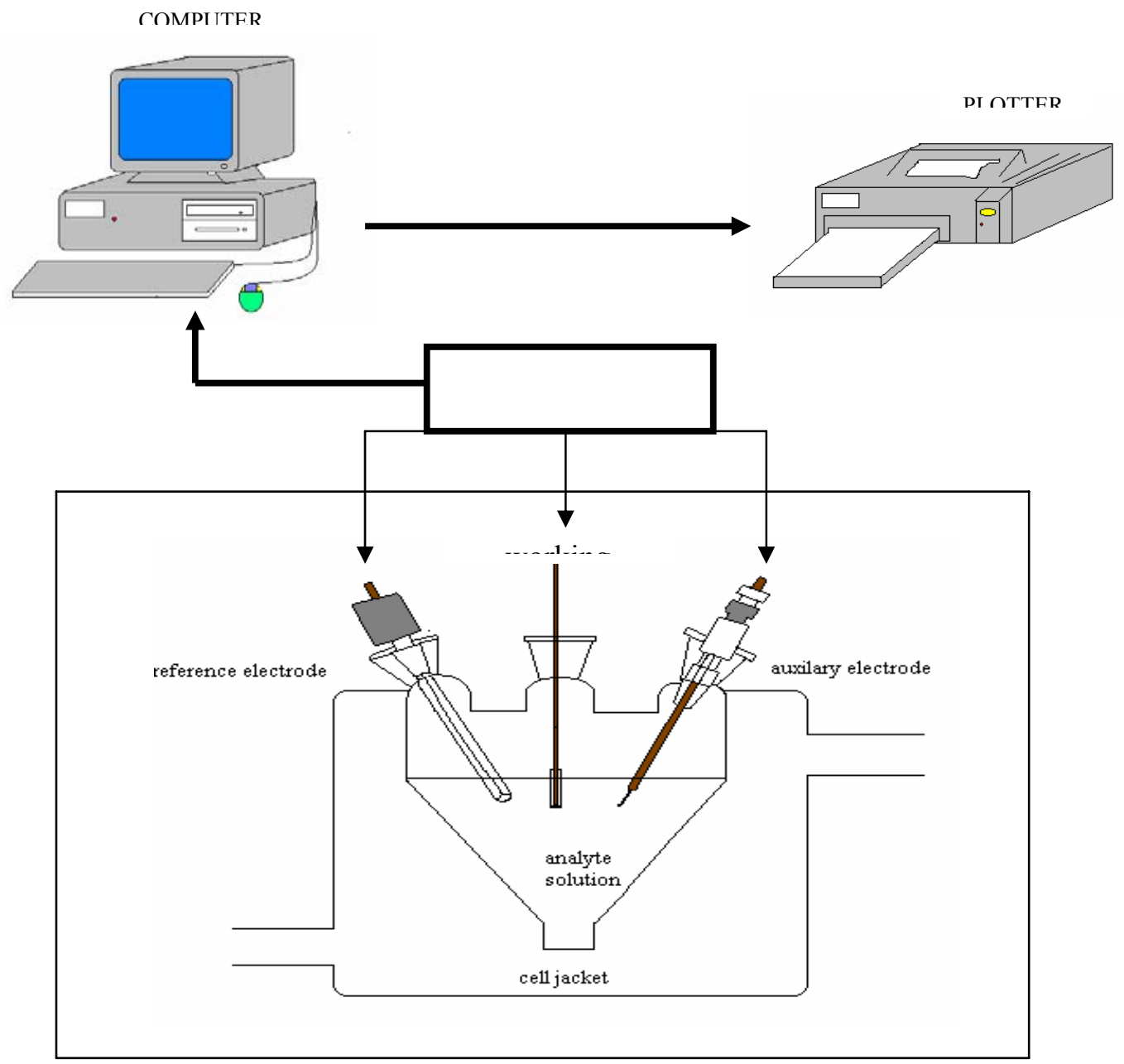

Figure 3 showed the CV scans commonly observed in the fabricated sensors in comparison with an unmodified sensor. Broadening of the cyclic voltammogram was observed in all modified electrodes. These could suggest that the modifiers used exhibited an inherent redox reaction at minimal extent. These however, did not significantly increase the charging current of the modified electrodes. It can be inferred that one of the desirable characteristics of the carbon paste electrodes which is low residual current (Khoo and Guo 1999) was preserved even with the addition of the modifier to the basic conductive material used.
Cyclic voltammetry was also employed as a preconditioning mechanism to eliminate any extraneous matter incorporated in the modified electrodes thus increasing the surface area available for metal binding. Results showed that all of the fabricated modified electrodes exhibit sufficient electroinactivity over a wide potential range of approximately $-1000-1000 \mathrm{mV}$. It was hence established that any signal observed during the voltammetric measurements of metal could be attributed to the analyte and not to any component of the working electrode. 


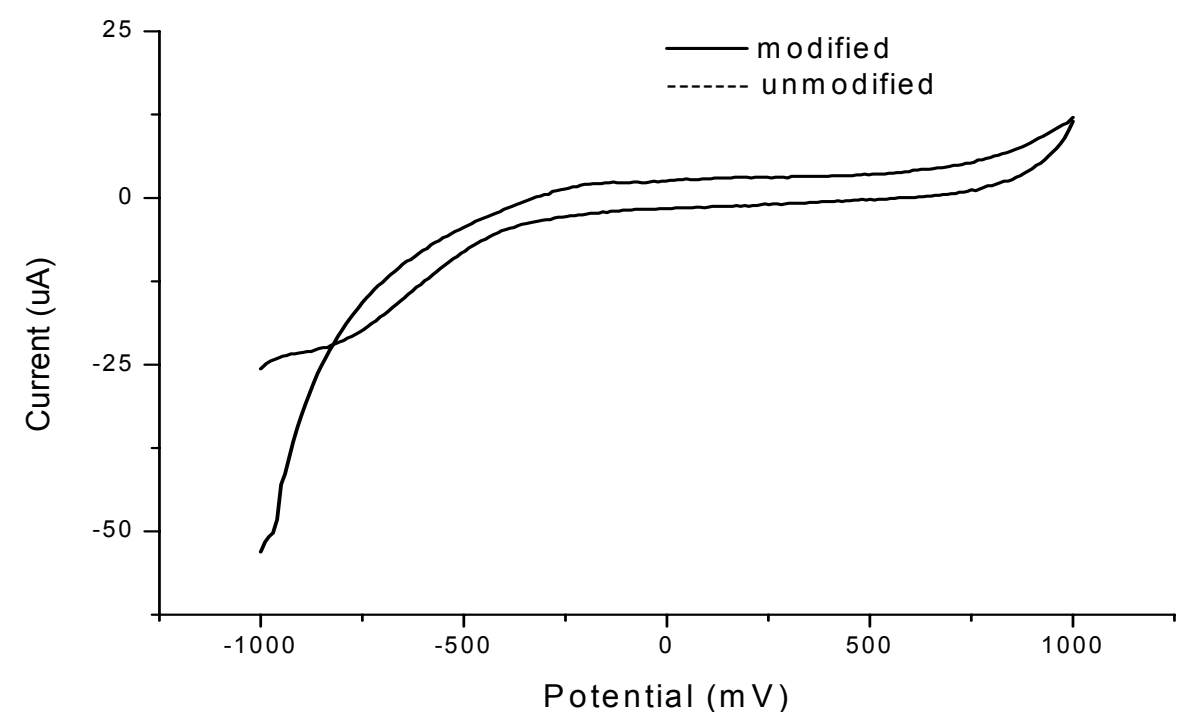

Fig 3. Cyclic voltammogram observed in all modified CPEs in comparison to umodified CPE (blank electrode).

Cyclic voltammetry was able to determine the presence of lead and mercury ions in aqueous solutions out of the five heavy metals tested. Figure 4 shows a typical cyclic voltammogram observed before and after preconcentration in a $1000 \mathrm{mg} \mathrm{L}^{-1}$ lead (II) solution on all of the fabricated modified electrodes. The $\mathrm{CV}$ produced a distinct peak at voltage range near $-500 \mathrm{mV}$, which is the voltage range for the reduction of lead ions (II) ions. Aside from this, mercury also gave a distinct peak around 0 $\mathrm{mV}$ (not shown). However, cyclic voltammetry can only determine the presence of lead and mercury ions. To determine if the metals really accumulated, differential pulse anodic stripping voltammetry (DPASV) was performed. A distinct peak was observed after the modified CPEs were placed in mercury and lead solutions (Figure 5). No peak was observed when unmodified CPE was used. For the three other metals, no peak was observed in both modified and unmodified CPEs. With these results, it is possible to utilize the fabricated modified CPEs as a voltammetric sensor for lead and mercury ions in aqueous samples like those found in the environment (i.e. lakes, rivers, wastewater etc.).

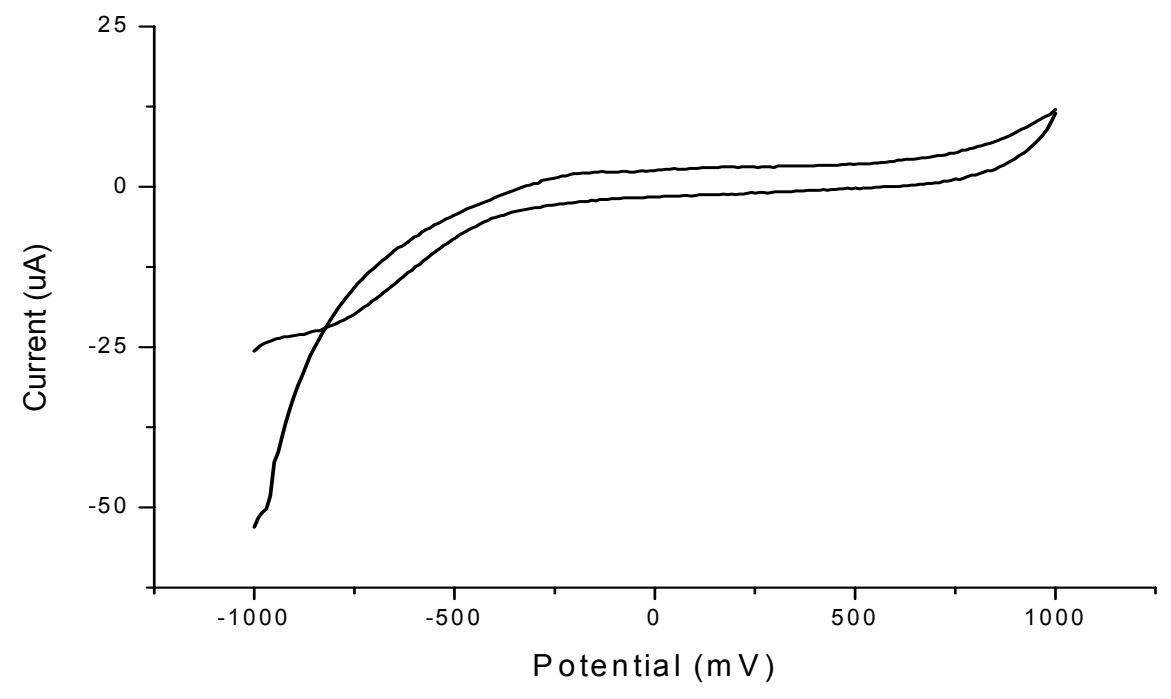

Fig 4. Cyclic voltammogram observed in all modified CPEs dipped in lead (II) solution.

The ability of mercury and lead ions to accumulate with the modified CPE could be due to the active ELMER-RICO E. MOJICA; JOSE RENE L. MICOR materials present in the modifiers thus altering the electrode surface. The plant parts used contain 
materials which can bind with the metals. Amino acid in protein can serve as a very effective ligand for a variety of metal ions since they contain a great number of potential donor atoms through the peptide backbone and amino acid side chains (Gooding et al
2001). Feathers, a protein with sulfur-containing amino acid was found to bind with lead ions (Mojica et al 2005) while lectin, a glycoprotein, was find to bind specifically with mercury ions (Mojica and Merca 2005).

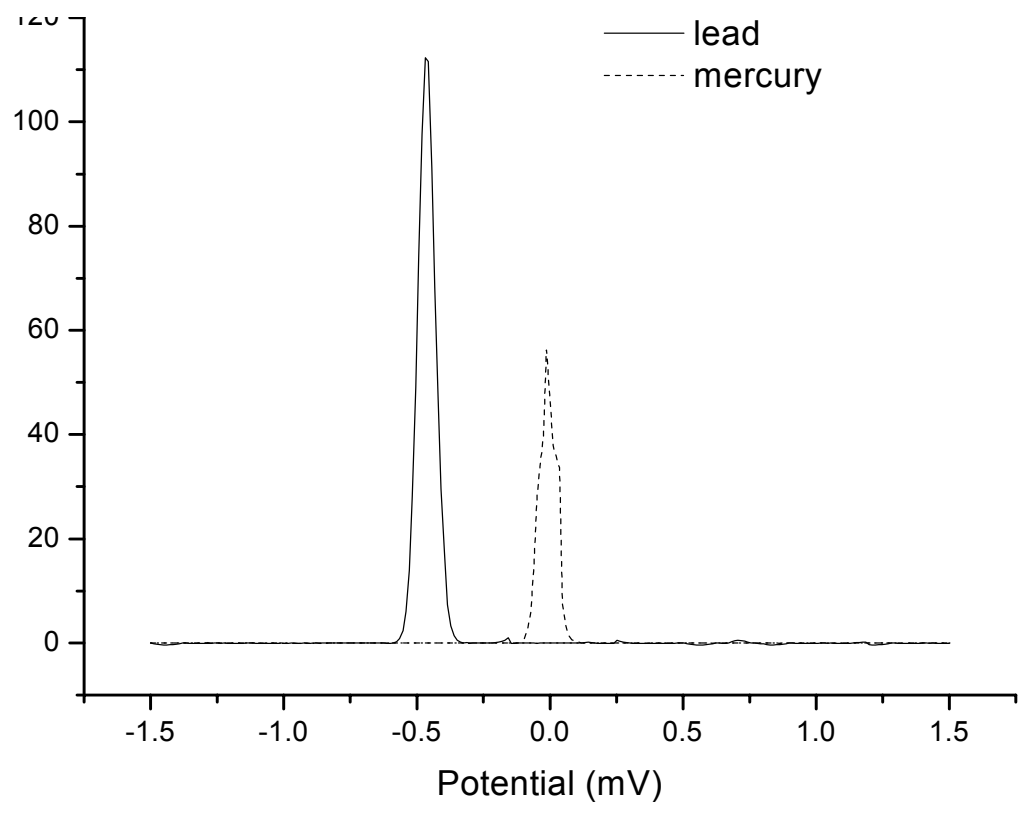

Fig 5. Differential pulse voltammogram of modified carbon paste electrode dipped at different metal solutions. The signals obtained for other metal solutions were all flat.

Aside from proteins, lignocellulosic materials could also be responsible for binding sites of metals. These materials were found to be responsible for the binding of lead ions in kapok fiber (Mojica et al 2002). Lignins are a group of phenolic polymers that contain an abundant amount of oxygen-containing functional groups such as phenolic, alcoholic and carboxylic structures that could possibly form ligninmetal macromolecular complexes with high stability through ionic, hydrogen and coordinate covalent bonding (Varma et al 1990). In addition, polysaccharide components like cellulose can also served as binding sites of metals by different mechanisms. One polymeric carbohydrate, alginic acid, was found to bind with lead ions by ion exchange mechanism (Wang et al 1991). It is also possible that the hydroxyl group and the carbonyl groups in the plant refuses are the main binding sites for heavy metals. Whatever are the materials present, the results showed that plant refuses have great potential as modifier of carbon paste electrodes for heavy metals like lead and mercury.

\section{REFERENCES}

Berman, E (1980). Toxic Metals and Their Analysis; Heyden. UK.
Blaylock, JM; Huang, JW. (2000). Phytoextraction of metals. In:Raskin, L., Ensley, B.D. (Eds.), Phytoremediation of Toxic Metals: Using Plants to Clean up the Environment. John Wiley and Sons, New York, pp. 53-70.

Brown, SL, Chaney, RL, Angle, JS, Baker, AJM. (1994). Phytoremediation potential of Thlaspi caerulescens and Blader Campion for zinc- and cadmium-contaminated soil. J. Environ. Qual. 23: 1151-1157.

Ensley, BD. (2000). Rationale for use of phytoremediation. In: Raskin, I., Ensley, B.D. (Eds.), Phytoremediation of Toxic Metals Using Plants to Clean Up the Environment. John Wiley and Sons, New York, pp. 3-12.

Ernst, WHO; Nilisse, HJM; Ten Brookum, WM. (2000). Combination toxicology of metalenriched soils: physiological responses of - and $\mathrm{Cd}$ resistant ecotypes of Silene vulgaris on polymetallic soils. Environ. Exp. Bot. 43: 55-71.

Gardea-Torresdey, JL; Arteaga S; Tiemann, KJ; Chianelli, R; Pingitore, N; Mackay, W. (2001). 
Absorption of copper (II) by creosote bush (Larrea tridentate): Use of atomic and $\mathrm{x}$-ray absorption spectroscopy. Environ. Toxicol. Chem. 20:2572-2579.

Glass, DJ. (2000). Economical potential of phytoremediation. In: Raskin, I., Ensley, B.D. (Eds.), Phytoremediation of Toxic Metals: Using Plants to Clean up the Environment. John Wiley and Sons, New York, pp. 15-31.

Gooding, JJ; Hibbert, DB; Yang, W. (2001). Electrochemical metal ions sensors, exploiting amino acids and peptides as recognitions elements. Sensors. 1:75-90.

Khoo, SB; Guo, SX. (1999). Rapidly renewable and reproducible electropolymerized surface at a monomer modified carbon paste electrode. J. Electroanal. Chem. 465: 102-113.

Manahan, SE (1993). Fundamentals of Environmental Chemistry; Lewis Publishers: Michigan,

Mojica, ERE; Gomez, SP; Micor JRL; Deocaris CC. (2006). Lead detection using a pineapple bioelectrode. Philippine Agricultural Scientist 89:134-140.

Mojica, ERE; Merca, FE. (2005). Anodic stripping voltammetric determination of mercury (II) using lectin modified carbon paste electrode. J. Applied Sci. 5:1461-1465.

Mojica, ERE ; Merca, FE ; Micor, JRL. (2002). Fiber of kapok (Ceiba pentandra) as component of a metal sensor for lead in water samples. Phillip. J. Crop. Sci. 27(2) :37-42.

Mojica, ERE, Tocino, AB; Micor JRL; Deocaris CC. (2005). A feather-trode sensor for detecting lead ions. Philipp. J. Sci. 134: 51-56.

Peralta, JR; Gardea-Torresdey, JL; Tiemann, KJ; Gomez, E; Arteaga, S; Rascon, E; Parsons, JG. (2001). Uptake and effect of five heavy metals on seed germination and plant growth in alfalfa (Medicago sativa). Bull. Environ. Contam. Toxicol. 66: 727-734.
Peralta-Videa, JR; Gardea-Torresdey, JL; Gomez, E; Tiemann, KJ; Parsons, JG; Carrillo, G. (2002). Effect of mixed cadmium copper, nickel, and zinc at different pHs upon alfalfa growth and heavy metal uptake. Environ. Pollut. 119:291301.

Rai, UN; Tripathi, RD; Vajpayee, P; Jha, V; Ali, MB. (2002). Bioaccumulation of toxic metals $(\mathrm{Cr}, \mathrm{Cd}$, $\mathrm{Pb}$, and $\mathrm{Cu}$ ) by seeds of Euryale ferox Salisb. (Makhana). Chemosphere. 46: 267-272.

Reeves, RD; Baker, AJM. (2000). Metal accumulating plants. In: Raskin, I., Ensley, B.D. (Eds.), Phytoremediation of Toxic Metals: Using Plants to Clean up the Environment. John Wiley and Sons, New York, pp. 193-229.

Schalcsha, E; Ahumada, IT (1998). Heavy metals in rivers and soils of Central Chile. Wat. Sci. Tech. 37: 251-255.

Varma, KVR; Swaminathan, T; Subrahmanyam, VPR. (1990). Heavy metal removal with lignin. J. Environ. Sci. Health. 25:243-265.

Velasco-Alinsug, MP; Rivero, GC; Quibuyen AO. (2005). Isolation of mercury-binding peptides in vegetative parts of Chromolaena odorata. Z Naturforsch [C]. 60:252-259.

Wyatt, CJ; Fimbres C; Romo L; Mendez, RO; Grijalva M. (1998). Incidence of heavy metal contamination in water supplies in Northern Mexico. Environ Res. 114-119.

Wang, J. (2000). Analytical Electrochemistry. 2nd ed. USA: VCH Publishers.

Wang, J; Taha, Z; Naser, N. (1991). Electroanalysis at modified carbon-paste electrodes containing natural ionic polysaccharides. Talanta. 38:81-88.

Yang, XE; Peng, HY; Jiang, LY; He ZL (2005). Phytoextraction of copper from contaminated soil by Elsholtzia spledens as affected by EDTA, citric acid and compost. Int. J. Phytoremediation. $7: 69-83$ 